
\title{
BResarch Soute \\ Ascent of the Conus Medullaris in Human Foetuses: A Systematic Review and Meta-Analysis
}

\section{Lucas Almeida}

Universidade Federal de Sergipe

Yasmin Juliany Figueiredo

Universidade Federal de Sergipe

André Zylberman

Universidade Federal de Sergipe

Diogo Garção ( $\nabla$ diogoufscar@yahoo.com.br)

Universidade Federal de Sergipe

\section{Research Article}

Keywords: conus medullaris, ascent, foetal development, spinal cord

Posted Date: October 27th, 2021

DOl: https://doi.org/10.21203/rs.3.rs-970944/v1

License: (c) (i) This work is licensed under a Creative Commons Attribution 4.0 International License.

Read Full License 


\section{Ascent of the conus medullaris in human foetuses: a systematic review and meta-analysis}

\section{Ascent of the conus medullaris in human fetuses: a systematic review and meta-analysis}

Lucas Costa Almeida ${ }^{1}$, Yasmin Juliany de Souza Figueiredo ${ }^{2}$, André Pinheiro Zylberman ${ }^{3}$, Diogo Costa Garção ${ }^{4}$

${ }^{1}$ Universidade Federal de Sergipe, Brazil, costa.lucas@academico.ufs.br

${ }^{2}$ Universidade Federal de Sergipe, Brazil, yasminjuliany@hotmail.com

${ }^{3}$ Universidade Federal de Sergipe, Brazil, andrepzylberman@outlook.com

${ }^{4}$ Graduation in Physiotherapy from Tiradentes University (2005), Master's (2009) and PhD (2013) in Physiotherapy from Universidade Federal de São Carlos.

\section{Reason for submission}

We believe that our manuscript is appropriate for Scientific Reports because of three main reasons: its findings are not population specific, so it can be applied globally, which is in consonance with the large scope of the journal; it's writing can be understood by non-specialists; and it's subject is interesting for multiples areas, such as neurosurgery, embryology and neonatology.

\section{Declaration}

There was no prior discussion with a Scientific Reports board member about the work described in our manuscript.

\section{Correspondence}

Diogo Costa Garção

Department of morphology

Center for Biological and Health Sciences

Federal University of Sergipe

Av. Marechal Rondon, s/n - Jardim Rosa Elze, São Cristóvão - SE, 49100-000 Phone (79) 21056621

diogoufscar@yahoo.com.br 


\begin{abstract}
The aim of the present systematic review and meta-analysis was to identify when the ascent of the conus medullaris occurs in human foetuses considering differences in evaluation methods and sample characteristics. Five databases were searched for relevant articles using different combinations of keywords. Article selection and data extraction were performed independently by two reviewers.

Disagreements were resolved by a third reviewer. The variables were distributed into four groups according to the gestational age of the specimens: I (13 to 18 weeks); II (19 to 25 weeks); III (26 to 32 weeks); IV (33 weeks to the probable date of birth). Eighteen articles were included. The majority used imaging exams as the evaluation method. Cadaveric dissections were reported in the remaining articles. Only morphological studies were included in the meta-analysis. Significant ascent occurs between groups I and III as well as groups II and IV. Despite the considerable heterogeneity among the studies included in the present review, the findings enabled the determination that the conus medullaris reaches its normal birth level by the $26^{\text {th }}$ week. Further analyses should be performed based on nationality and ethnicity to diminish the heterogeneity of the data.
\end{abstract}

Keywords: conus medullaris; ascent; foetal development; spinal cord.

\title{
Introduction
}

The spinal cord (SC) is a cylindrical structure of the central nervous system between the brainstem and the lower edge of the first lumbar vertebra. The SC receives peripheral information and controls voluntary muscles of the torso and limbs. Despite the segmentary organisation, there are no macroscopical limits between the segments of the SC. Structurally, the SC has cervical and lumbosacral enlargements, from which nerve roots originate and extend to the upper and lower limbs, respectively (Bican, 2013).

Topographically, the SC resides inside the spinal canal but only occupies part of the length of the canal after birth. The filum terminale is a delicate strand of fibrous tissue that attaches the lowest part of the SC, denominated the conus medullaris, to the coccyx $(\mathrm{Qu}, 2017)$. 
During foetal development, the conus medullaris (CM) ascends from a lower position in the spinal canal to its final location at birth (approximately at the level of the L2 vertebra) (Zalel, 2006; Arthurs, 2013). During intrauterine life, non-linear growth of the spinal cord occurs relative to the spinal canal, which is the main cause of the apparent ascent of the CM (Bican, 2013).

The main methods reported in the literature for the evaluation of the position of the $\mathrm{CM}$ and its ascent are anatomical studies on post-mortem foetuses (Igten, Memedova, \& Siillti, 1995) and imaging exams, such as sonography (Rozellle et al., 2013) and magnetic resonance (Huang et al., 2013). With ultrasound, the $\mathrm{CM}$ is identified as a dark triangular structure with two surrounding echogenic lines at the caudal portion of the SC (Malas, 2000; Hoopmann, 2011). The common methods for investigating the ascent of the $\mathrm{CM}$ are the determination of its position in relation to spinal level and the measurement of the distance between the CM and the last sacral vertebra (Zhai, 2018).

Knowledge of the normal growth pattern of the SC and its components can assist in understanding its development and birth defects. For example, a lower CM may indicate inadequate ascent, which raises suspicions of occult spinal dysraphism (Miao, 2019). Several studies have reported that the determination of the location of the $\mathrm{CM}$ is valuable for the diagnosis of tethered cord syndrome. Prenatal diagnosis of this syndrome is important to determining the prognosis of affected foetuses. However, the detection of minor deformities of the foetal SC within the uterus remains a challenge (He et al., 2020).

Information on the foetal CM can be used to guide to lumbar punctures, surgeries, and imaging studies of the neonate SC, especially when signs indicate tethered spinal cord or other anomalies. This is particularly important, as surgeries performed after the occurrence of symptoms have a low probability of correcting the neurological damage, but deterioration can be arrested if the procedure is successful (Robbin, 1994; Rowland, 1995; Sahin, 1997). Moreover, a dataset on normal CM development could be used as a reference for comparisons to potentially pathological conditions. However, the precise moment of $\mathrm{CM}$ ascent remains unknown, and the literature offers conflicting data, which hinders the establishment of a clear pattern (Zalel, 2006). 
Therefore, the aim of the present systematic review and meta-analysis was to identify when the ascent of the conus medullaris occurs in human foetuses considering differences in evaluation methods and study samples. An additional objective was to determine whether there is a CM ascent pattern.

\section{Method}

Outline of study

This review was conducted in accordance with the guidelines specified in the Cochrane Collaboration Handbook, Version 5.2. The protocol for this systematic review was registered in the PROSPERO database (Registration code: CRD42020200839).

The research question was formulated using the POT acronym (Population - Outcome Type of study), the aim of which is to systematise and optimise the search process in databases. Using the established criteria (P, human foetuses; $\mathrm{O}$, ascent of the CM; and T, cross-sectional anatomical studies), the following question was posed: When does the ascent of the CM occur in human foetuses?

Search strategy

Five online databases were searched for articles meeting the pre-established criteria: National Library of Medicine (MEDLINE-PubMed), SciELO, Web of Science, Lilacs, and Scopus. Different combinations of the following keywords were used by two independent researchers: “evaluation”, “conus medullaris”, “position”, “development”, “spinal cord”, "human foetus”, “distance”, and "anatomy". After the retrieval of relevant references, the titles were analysed and duplicates were removed.

Study selection

Two reviewers performed the article selection process in two stages: analysis of abstracts for potentially eligible articles and full-text analysis. Divergences of opinion were resolved by consulting a third impartial reviewer. The following were the inclusion criteria: studies on human foetuses; gestational ages between 13 and 40 weeks; the use of appropriate methods to locate the CM, such as magnetic resonance, dissection, or ultrasound. Studies that only used foetuses with brain or spine 
abnormalities, systematic reviews, case reports, and meta-analyses were excluded. Papers from the $20^{\text {th }}$ century were also included, as the dissection methodology was only used in this period.

\section{Data extraction}

Two reviewers performed the data extraction independently, with the participation of a third impartial reviewer to resolve disagreements, when needed. The following data were collected: main author's name, publication date, duration of the study, nationality of the specimens, analysis method, number of foetuses, proportion between males and females, number of foetuses by gestational age, location of the $\mathrm{CM}$ in the spine, formula for comparing gestational age and $\mathrm{CM}$ distance to a reference measure, formula for comparing femur size and CM distance to a reference measure, and measures taken to diminish intra-observer and inter-observer variability.

The methodological quality (risk of bias) of the studies was appraised using the Anatomical Quality Assurance (AQUA) tool designed by the International Evidence-Based Anatomy (iEBA) working group (Tomaszewski, 2017). The AQUA tool probes for risk of bias in five domains (objectives and subject characteristics; study design; characteristics of methods; descriptive anatomy; and reporting of results). The risk of bias for each domain is classified as 'high', 'low' or 'unclear'.

\section{Meta-analysis}

The L2 level was established as a parameter, as it is approximately the final location of the CM at birth (Zalel, 2007; Arthurs, 2013; CJ Rozelle, 2013; Albert-Neels Van Schoor, 2015). Therefore, meta-analysis was conducted by gestational age to determine the frequency of the CM at or above L2. To compare the results, the distribution of the data (normal or non-normal) was determined using the Kolmogorov-Smirnoff test, followed by the Kruskal-Wallis test with Dunn's post-hoc test $(\mathrm{p}<0.05)$.

\section{Statistical analysis}

To improve the evaluation and unify heterogeneous data, the variables were distributed into four groups according to the gestational age of the specimens: I (13 to 18 weeks); II (19 to 25 weeks); III (26 to 32 weeks); IV (33 weeks to the probable date of birth). In one study, a gestational age of 40 weeks was established as birth. 
Considering this division, every specimen received a score from 1 to 5 depending on the location of the CM in the lumbar spine: 1 - L5; 2 - L4; 3 - L3; 4 - L2; 5 - L1. For foetuses with a CM in an intervertebral position, the lower vertebra was considered. Using these data, the Kruskal-Wallis test was performed followed by Dunn's post hoc test $(\mathrm{p}<0.05)$ to determine the occurrence of significant differences among groups. Pearson's correlation test $(p<0.05)$ was also used to determine the occurrence of correlations between CM location and gestational age.

\section{Results}

Article selection

The search led to the retrieval of 1160 potentially relevant studies. After the removal of duplicates and screening of the titles, 41 abstracts were submitted to analysis, leading to the exclusion of 14 articles for not mentioning the position of the CM or involving abnormal foetuses. After the full-text analyses, nine articles were excluded for not meeting inclusion criteria, mainly due to studying new-borns rather than foetuses. At the end of the selection process, 18 articles were included in the present systematic review and meta-analysis (Figure 1).

\section{Characteristics of studies included}

Among the 18 studies ( $\mathrm{n}=3189$ useful foetuses), 15 used imaging exams as the evaluation method: sonography (12 studies; 2752 useful foetuses; 66.7\%) and magnetic resonance (three studies; 158 useful foetuses; $16.7 \%$ ). The remaining studies involved visual analyses during cadaveric dissections (three studies; 279 useful foetuses; 16.7\%). Eleven of the studies (61.1\%) performed morphological analyses, comparing the CM to its corresponding vertebral level. Six studies $(33.3 \%)$ performed morphometric analyses, measuring the distance between the CM and a selected position of the sacrum. One study (5.6\%) used both types of analysis. Only morphological results were considered in the meta-analysis.

The largest number of studies were from Europe (seven studies; 1525 useful foetuses; 47.8\%), followed by Asia (six studies; 1414 useful foetuses; 44.3\%), the Middle East (three studies; 213 useful foetuses; 6.8\%), South America (one study; 24 useful foetuses; 0.7\%), and North America (one study; 13 useful foetuses; $0.4 \%$ ). Only nine articles mentioned the study period (range: three months to seven years). The years of publication ranged from 1970 to 2019 (Table 1). 
Appraisal of methodological quality

The AQUA tool revealed that two studies (11.1\%) had a high risk of bias in the first domain (objective and subject characteristics) and nine (50.0\%) had a high risk in the third domain (characteristics of methods). This was mainly due to the lack of demographic data presented in the studies and the omission of the researchers' experience and measures taken to lower intra-observer and inter-observer variability. All papers had a low risk of bias regarding the second, fourth, and fifth domains (study design, descriptive anatomy, and reporting of results, respectively) (Table 2).

\section{Primary outcome}

Among the 12 studies with a morphological analysis, one (8.3\%; Robbin, ML 1994) was not included in the meta-analysis for not reporting the age of the foetuses. All foetuses in Group I (15.91 $\pm 0.14 ; 128$ useful foetuses) had a CM lower than vertebral level L2. In Group II (22.27 $\pm 0.07 ; 577$ useful foetuses), the frequency of the CM at L2 or above was 0.16 , with a high rate of heterogeneity among the studies $\left(\mathrm{I}^{2}=80 \%\right)$. This figure increased to $0.42\left(\mathrm{I}^{2}=93 \%\right)$ in the seven studies that used foetuses in Group III $(29.12 \pm 0.10 ; 379$ useful foetuses $)$ and $0.82\left(I^{2}=91 \%\right)$ in the six studies that used foetuses in Group IV (35.76 $\pm 0.12 ; 344$ useful foetuses) (Figure 2). Thus, a statistically significant ascent of the CM occurred between Groups I and III as well as between Groups II and IV considering the frequency at L2 or above ( $\mathrm{p}<0.05$, Kruskal-Wallis test and Dunn's post hoc test) (Figure 3). This analysis demonstrates that the foetal CM begins to reach vertebral level L2 in the $26^{\text {th }}$ week, but a high rate of variability was found among the studies.

Significant differences were found regarding the average vertebral level (L1 to L5) that the CM reached per group $(\mathrm{p}<0.05$, Kruskal-Wallis test and Dunn's post hoc test) (Figure 4). This indicates that the ascent of the conus medullaris occurs throughout the entire period considered in this meta-analysis (from 13 weeks to the probable date of birth). Moreover, a strong positive correlation $(\mathrm{r}=$ $0.86 ; \mathrm{p}<0.05$ ) was found between the average age in the four groups and the average position of the CM on each group (Figure 5), demonstrating that the ascent process is directly correlated with gestational age. 
Considering the seven studies with morphometric analysis $(n=2284$ useful foetuses), five

(71.4\%) measured the distance between the CM and the last sacral centre of ossification (CS distance) and two (28.6\%) measured the distance between the CM and S1 (CS1 distance).

Secondary outcome

Considering only the morphological studies, the CM was lower than the L2 level in all foetuses in Group I, independently of the evaluation tool (anatomic dissection, sonography, or magnetic resonance). In the studies involving in post-mortem foetuses in Group II, the frequency of the CM at L2 or above was $0.05\left(I^{2}=79 \%\right)$, whereas this figure was higher in Groups III and IV (0.10 and 0.50, respectively). Only one study (Barson AJ, 1970) had useful foetuses in these two intervals.

Among the morphological studies that employed ultrasound, the frequency in Groups II and III was respectively $0.22\left(\mathrm{I}^{2}=97 \%\right)$ and $0.60\left(\mathrm{I}^{2}=98 \%\right)$, whereas this figure increased to 0.94 in Group IV $\left(\mathrm{I}^{2}=45 \%\right)$. In the studies that employed magnetic resonance, the frequency in Groups II and III was respectively $0.08\left(\mathrm{I}^{2}=1 \%\right)$ and $0.28\left(\mathrm{I}^{2}=0 \%\right)$, whereas this figure was 0.82 in Group IV $\left(\mathrm{I}^{2}=91 \%\right)$ (Figure 6).

The variables addressed in the morphometric studies were gestational age (seven; $100 \%$ ), femur size (six; 85.7\%), biparietal diameter (three; 42.9\%), abdominal circumference (three; 42.9\%), head circumference (two; $28.6 \%$ ), and foetal position (one; 14.3\%). The studies analysed the data using linear regressions, which showed significant associations between these variables and the measurement of choice (CS distance or CS1 distance).

Only four of the studies included in the present review (22.2\%) compared the ascent of the conus medullaris in male and female foetuses and none found a significant difference between sexes.

\section{Discussion}

The studies included in the present systematic review revealed different CM ascension patterns. Barson et al. (1970) suggest early ascension at 35 weeks, justified by slight disparity in the development of the SC when compared to the spine, with unequal growth patterns in the lumbar portion in relation to the other axial segments. 
Manzone et al. (2019) analysed the growth pace of the spine and SC, reporting steady,

dissimilar values. The asymmetry between the SC level and spine is due to the disproportional growth of the two structures, which results in the ascent of the CM from S1 to L2 in the second trimester of pregnancy. These results were evident in this systematic review, which showed that the CM begins to appear above L2 between 19 to 25 weeks of pregnancy, with a progressively increasing frequency accompanying the increase in gestational age.

The present systematic review and meta-analysis showed that the CM reached level L2 or higher starting in the $26^{\text {th }}$ week in most studies. However, some studies reported an earlier ascent, such as the one conducted in India by Vettivel et al. (1991) using the anatomical dissection of post-mortem foetuses as the evaluation method, in which the CM was at level L2 or above in half the samples with a gestational age of 19 to 25 weeks.

The present results show that the $\mathrm{CM}$ ascension process occurs progressively through to the last weeks of pregnancy. In agreement with this finding, a study with magnetic resonance on post-mortem foetuses conducted in the United Kingdom found additional CM ascension in the third trimester of pregnancy (Arthurs et al., 2013). In contrast, Widja et al. (2006) conducted a study in the United Kingdom involving a similar analysis and presented limited available data, leading to high variability in the CM position under 35 weeks of pregnancy, despite the fact that the authors found significant linear correlations between vertebral body height and disc as well as between the ossification area of the vertebral centre and gestational age. The authors concluded that the CM ascension process is nearly concluded in the first two trimesters of gestation.

A study conducted in China involving morphological and morphometric analyses on a sample of 521 healthy foetuses of both sexes used ultrasound to measure the CM-S1 distance. The authors found that the foetuses began to present the CM at L2 in the $22^{\text {nd }}$ week and that the CM was at or above L3 in the entire sample after 23 weeks. The CM was above L2-3 after 32 weeks and above L2 in most foetuses with a gestational age of 37 weeks (Zhai et al., 2018).

Based on the correlation between average vertebral level and the $\mathrm{CM}$, the present review revealed that the ascension of this structure occurs throughout the entire period considered, with sharp 
increase between the $10^{\text {th }}$ and $25^{\text {th }}$ weeks of pregnancy. During this period, the CM leaves the L5 level and reaches L3 in most cases, ascending progressively up to L2 or higher from the $26^{\text {th }}$ week until birth.

Regarding morphology, the three studies (Zhao, 2017; Rodriguez, 2016; He, 2016) that addressed the distance between the CM and the end of the sacrum performed analyses according to gestational age group. In the studies that addressed the CM-S distance, only one (Zhai, 2018) distributed the sample by gestational age group, while the other articles (Rodriguez, 2014; Hoopmann, 2011; Mottet, 2016) did not describe any division of the samples considering foetal age. In the present systematic review, all studies found statistically a significant correlation between CS distance and gestational age. Thus, the disparity between spine development and the SC during the weeks of gestation justifies the ascension of the $\mathrm{CM}$, confirming the strong positive correlations between the average age in the four groups and the location of the $\mathrm{CM}$ in each.

The studies that used post-mortem foetuses with either dissection (Barson, 1970; Malas, 2000) or post-mortem magnetic resonance (Arthur, 2013; Manzone, 2019) presented similar, low frequencies of foetuses with the CM at L2 from 19 to 25 weeks. In contrast, studies involving ultrasound performed on live foetuses (Zael, 2006; Perlitz, 2010; Zhai, 2018) found that the CM was at L2 in approximately half of the entire sample of foetuses with gestational age from 19 to 25 weeks.

Furthermore, an Indian study with a post-mortem sample (Rao et al., 1949) that evaluated the location of the $\mathrm{CM}$ through anatomical dissection reported levels above L2 in foetuses with a gestational age of 19 to 25 weeks. This divergence may be explained by the influence of ethnicity. The study reports that foetuses in southern India had a tendency toward higher CM ascension compared to those in northern India, consequently reporting a higher frequency of foetuses at or above L2 at a lower gestational age compared to data from other post-mortem studies. Vettivel et al. (1991) confirmed this hypothesis, demonstrating a tendency toward positioning up to one vertebra above the average in gestational age groups among foetuses in southern India compared to those in northern India. Thus, the high variability in the position of the CM throughout the weeks of pregnancy weeks found in the present systematic review and meta-analysis could be influenced by the inclusion of studies with different ethnicities. 
There are many reasons why post-mortem studies can present dissimilar results. The state and time of foetus conservation may influence the position of the SC. This may occur due to a postural change in vertebral kyphosis influenced by an element of non-physiological severity that diminishes the curvature and, consequently, reduces the CM level (Arthurs, 2013).

Regarding the morphometric approach, Hoopman et al. (2011) standardised this analysis using anatomical landmarks, such as the distance between the most caudal portion of the CM and the last ventral ossification centre of the sacrum $(\mathrm{CS} 1)$. To identify S1, the studies evaluated lumbosacral curvature using ultrasound. This approach was performed with the use of two tangents drawn at the last lumbar and sacral ossification nuclei from bottom to top, the intersection of which was the CM (Rodriguez et al., 2014; He et al., 2016; Rodriguez \& Prats, 2016; Mottet et al., 2016; Zhao et al., 2017; Zhai et al., 2018).

Besides the morphometric method, the use of formulas to predict the normal CM ascension pace enables a more reliable assessment of SC development (Lei et al., 2014). The seven morphometric studies included in this systematic review conducted linear regressions and found associations between the progressive ascension of the CM and gestational age, femur length, biparietal diameter, and BMI.

Thus, the routine quantification of the CS1 distance in imaging exams is viable. An early assessment could help diagnose spinal dysraphism, tethered SC, and other problems related to SC development. Prior detection is important to prepare parents for the anomaly and enable physicians to develop a surgical repair strategy in a timely manner to avoid irreversible neurological damage (Rodríguez, 2016).

Regarding sexual dimorphism, despite the small number of studies that addressed this variable, no significant association was found among the articles included in the present review. Manzone \& Guidobono (2019) found no statistically significant difference in SC length between male and female foetuses in an Argentinian study performed with magnetic resonance. Perlitz et al. (2010) used ultrasound to analyse Israeli foetuses and also found no difference in CM position between the sexes.

\section{Study Limitations}


The main limitation of the present systematic review and meta-analysis is the high level of heterogeneity, which may be explained by the unequal distribution of studies among different countries. The lack of studies including different ethnicities makes it difficult to establish a global pattern of CM ascent. Moreover, the different methods of viewing the $\mathrm{CM}$ and assessing the $\mathrm{CM}$ level can exert an influence on the analysis and contribute to the highly heterogeneous data.

\section{Conclusion}

This systematic review and meta-analysis concluded that the CM reaches the birth level (L2) in the $26^{\text {th }}$ week of pregnancy. This information can be used to compare potentially anomalous cases to the clinically normal development of the CM. However, due to the ethnic differences, the different methods of viewing the CM, and the different methods of assessing CM level, the dataset was highly heterogeneous. Further analyses should be performed according to nationality and ethnicity to enable the description of possible CM ascension pattern by ethnic group and decrease the degree of heterogeneity in currently available data.

\section{References}

1. Bican, O., Minagar, A., \& Pruitt, A. A. The spinal cord: a review of functional neuroanatomy. Neurologic clinics, 31(1), 1-18 (2013).

2. Qu Z, Qian B, Qiu Y et al. Does the position of conus medullaris change with increased thoracolumbar kyphosis in ankylosing spondylitis patients?. Medicine. 96, 6(e5963) (2017).

3. Zalel Y, Lehavi O, Aizenstein O et al.. Development of the Fetal Spinal Cord Time of Ascendance of the Normal Conus Medullaris as Detected by Sonography. J Ultrasound Med. 25:1397-1401 (2006).

4. Arthurs OJ, Thayyil S, Wade A, et al. Normal ascent of the conus medullaris: a post-mortem foetal MRI study. J Matern Fetal Neonatal Med. 26(7), 697-702 (2013).

5. Igten N, Memedova E, Siillti Y. Vertebral level of the ending of the spinal cord and its relationship to the length of the vertebral column in Northern Turkish neonates. Surg Radiol Anat. 17(4), 315-81995 (1995).

6. Rozzelle CJ, Reed GT, Kirkman JL et al. Sonographic determination of normal Conus Medullaris level and ascent in early infancy. Childs Nerv Syst. 30(4), 655-8 (2014).

7. Huang YL, Wong AM, Liu HL, et al. Fetal magnetic resonance imaging of normal spinal cord: evaluating cord visualization and conus medullaris position by T2-weighted sequences. Biomed J. 37(4), 232-236 (2014). 
8. Malas MA, Seker M, Salback A. The relationship between the lumbosacral enlargement and the conus medullaris during the period of fetal development and adulthood. Surg Radiol Anat. 22: 163-168 (2000).

9. Hoopmann M, Abele H, Yazdi B et al.. Prenatal evaluation of the position of the fetal conus medullaris. Ultrasound Obstet Gynecol. 38: 548-552 (2011).

10. Zhai J, Cai A, Wei Q et al.. A Method for Quantitative 2-Dimensional Sonographic Analysis of the Fetal Conus Medullaris Position. J Ultrasound Med. 00, 1-6 (2018).

11. Miao M, Lin X, Zhang Z et al.. Normal development of the fetal spinal canal and spinal cord at T12 on 3.0-T MRI. Acta Radiol. 60(5), 623-627 (2019).

12. He S, Ruan J, Wang X et al.. Measurement of fetal conus distance with 3D ultrasonography as a reliable prenatal diagnosis method for tethered cord syndrome. Journal of Obstetrics and Gynaecology Research. 46(4), 587-594 (2020).

13. Robbin ML, Filly AR, Goldstein RB. The Normal Location of the Fetal Conus Medullaris. $J$ Ultrasound Med. 13, 541-546 (1994).

14. Rowland Hill CA, Gibson PJ. Ultrasound Determination of the Normal Location of the Conus Medullaris in Neonates. AJNR Am J Neuroradiol. 16, 469 -472 (1995).

15. Sahin F, Selçuki M, Ecin N et al. Level of conus medullaris in term and preterm neonates. Archives of Disease in Childhood. 77, 67-69 (1997).

16. Tomaszewski, K. A., Henry, B. M., Kumar Ramakrishnan, P., Roy, J., Vikse, J., Loukas, M., Tubbs, R. S., \& Walocha, J. A. Development of the Anatomical Quality Assurance (AQUA) checklist: Guidelines for reporting original anatomical studies. Clinical anatomy (New York, N.Y.), 30(1), 14-20 (2017).

17. Van Schoor AN, Bosman MC, Bosenberg AT. Descriptive study of the differences in the level of the conus medullaris in four different age groups. Clin Anat. 28(5), 638-44 (2015).

18. Barson AJ. The vertebral level of termination of the spinal cord during normal and abnormal development. J Anat. 106(Pt 3), 489-497 (1970).

19. MANZONE, P., GUIDOBONO, J. A., \& FORLINO, D.. Longitudinal development of the spine and spinal cord in human fetuses. Coluna/Columna. 19(1), 8-12 (2020).

20. Vettivel S. Vertebral level of the termination of the spinal cord in human fetuses. J Anat. 179, 149-161 (1991).

21. Widjaja E, Whitby EH, Paley MN et al.. Normal fetal lumbar spine on postmortem MR imaging. AJNR Am J Neuroradiol. 27(3), 553-559 (2006).

22. Zhao D, Wei Q, Cai A et al.. Prenatal Assessment of the Position of Fetal Conus Medullaris as a Predictor of Fetal Spinal Lesions. J Ultrasound Med. 37(1), 201-207 (2018).

23. Rodríguez MA, Prats P, Rodríguez I et al.. Prenatal Evaluation of the Fetal Conus Medullaris on a Routine Scan [published correction appears in Fetal Diagn Ther. 2016;39(2):157]. Fetal Diagn Ther. 39(2), 113-116 (2016). 
24. He SZ, Lv GR, Liu SL et al.. Prenatal Ultrasound Evaluation of the Position of Conus Medullaris for the Diagnosis of Tethered Cord Syndrome. Ultrasound Q. 32(4), 356-360 (2016).

25. Rodriguez MA, Prats P, Muñoz A et al. Sonographic evaluation of the fetal conus medullaris. Prenat Diagn. 34(11),1111-1114 (2014).

26. Mottet N, Saada J, Jani J et al. Sonographic Evaluation of Fetal Conus Medullaris and Filum Terminale. Fetal Diagn Ther. 40(3), 224-230 (2016).

27. Perlitz Y, Izhaki I, Ben-Ami M. Sonographic evaluation of the fetal conus medullaris at 20 to 24 weeks' gestation. Prenat Diagn. 30(9), 862-864 (2010).

28. Rao VS, The lower limit of spinal cord in South Indian foetuses. Journal of Anatomy. 83, 175 (1949).

29. Lei T, Xie HN, Zheng J et al. Prenatal evaluation of the conus medullaris position in normal fetuses and fetuses with spina bifida occulta using three-dimensional ultrasonography. Prenat Diagn. 34(6), 564-569 (2014).

30. Yang SH, Yang ZJ, Li YY et al.. Localization of the fetal conus medullaris by oblique view extended imaging. J Med Ultrason. 44(4), 281-287 (2017).

Funding: This research did not receive any specific grant from funding agencies in the public, commercial, or not-for-profit sectors.

Competing interests: The authors declare no potential conflict of interest.

\section{Author Contribution}

LC Almeida: Data collection, Manuscript writing;

YJ Figueiredo: Data collection, Manuscript writing;

AP Zylberman: Data analysis, Manuscript writing;

DC Garção: Protocol/project development.

Figure 1. Flowchart of article selection process in accordance with PRISMA guidelines.

Figure 2. Frequency of foetuses with $\mathrm{CM}$ at L2 or above by gestational age group.

Figure 3. Average frequency of foetuses with CM at L2 or above by gestational age group.

Figure 4. Average position of CM by gestational age group.

Figure 5. Correlation between gestational age and CM position.

Figure 6. Frequency of foetuses with CM at L2 or above distributed by gestational age group and evaluation tool: post-mortem, sonography, and MRI (from left to right). 
Table 1. Characteristics of studies included in present review

\begin{tabular}{|c|c|c|c|c|c|}
\hline Studie & Natonality & Analysis method & Assessment tool & Useful sample & GA (weeks) \\
\hline Barson, $1970[9]$ & England & Morphological & Post mortem & 189 & 13 - Birth \\
\hline Vettivel, $1991[10]$ & india & Morphological & Post montem & 65 & $10-24$ \\
\hline Robbin et a, $1994[6]$ & USA & Morphoiogical & Utrasound & 13 & $19-36$ \\
\hline Malas et $a t, 2000$ [1] & Turkey & Morphological & Post mortem & 25 & $14 \cdot 19$ \\
\hline Zalel et $a, 2006$ [3] & Israel & Morphological & Utrasound & 110 & 13 - Birth \\
\hline Pencizz et al, 2010 [11] & israel & Morphological & Utrasound & 78 & $20-24$ \\
\hline Hoopmann et al, $2011[2]$ & Germany & Morphometric & Utrasound & 254 & 15 - Birth \\
\hline Arthurs et al, 2013 [12] & Germany & Morphological & MRI & 84 & $14-39$ \\
\hline Huang et al, $2013[13]$ & Taiwan & Morphological & MRI & 50 & $20-38$ \\
\hline Les et $a l, 2014$ [14] & Ching & Morphological & Utrasound & 145 & $20-38$ \\
\hline Rodriguez et at, 2014 [15] & Spain & Morphometric & Utrasound & 101 & $20-32$ \\
\hline He ef ar, $2016[16]$ & China & Morphometric & Utrasound & 511 & 14 - Birth \\
\hline Rodriguez \& Prats, 2016 [17] & Spain & Morphometric & Uetrasound & 573 & $20-35$ \\
\hline Mottet et al, 2016 [18] & France & Morphometric & Utrasound & 164 & $17 \cdot 37$ \\
\hline Zhao ef al, 2017 [19] & Austria & Morphometric & Utrasound & 160 & $20-28$ \\
\hline Yang et al, 2017 [20] & China & Morphological & Uetrasound & 122 & $20-30$ \\
\hline Zhai et at, 2018 [4] & China & $\begin{array}{l}\text { Morphoiogical e } \\
\text { morphometric }\end{array}$ & Utrasound & 521 & $20-28$ \\
\hline Manzone \& Guidobono, $2019[21]$ & Argentina & Morphological & MRI & 24 & $13 \cdot 22$ \\
\hline
\end{tabular}

Table 2. Results of appraisal of methodological quality using AQUA tool

\begin{tabular}{|c|c|c|c|c|c|}
\hline \multirow[b]{2}{*}{ Studie } & \multicolumn{5}{|c|}{ Domains } \\
\hline & 1 & 2 & 3 & 4 & 5 \\
\hline Barson, 1970 [9] & - & - & - & - & - \\
\hline Vettivel, $1991[10]$ & - & - & + & - & - \\
\hline Robbin et al., $1994[6]$ & + & - & + & - & - \\
\hline Malas et al, $2000[1]$ & - & - & + & - & - \\
\hline Zaiel et al., $2006[3]$ & - & - & + & - & - \\
\hline Perlitz ef al, 2010 [11] & - & - & + & - & - \\
\hline Hocpmann ef al, 2011 [2] & - & - & + & - & - \\
\hline Avthurs ef al., 2013 [12] & - & - & - & - & - \\
\hline Huang et al, 2013 [13] & + & - & + & - & - \\
\hline Lel et al., $2014[14]$ & - & - & - & - & - \\
\hline Rodriguez et al, 2014 [15] & - & - & - & - & - \\
\hline He et at, 2016 [16] & - & - & - & - & - \\
\hline Rodriguez \& Prats, 2016 [17] & - & - & - & - & - \\
\hline Mottet et al, 2016 [18] & - & - & - & - & - \\
\hline Zhao et at, 2017 [19] & - & - & - & - & - \\
\hline Yang et af, 2017 [20] & - & - & - & - & - \\
\hline Zhat ef al, 2018 [4] & - & - & + & - & - \\
\hline Manzone \& Guidobono, 2019 [21] & - & - & + & - & - \\
\hline
\end{tabular}


Figures

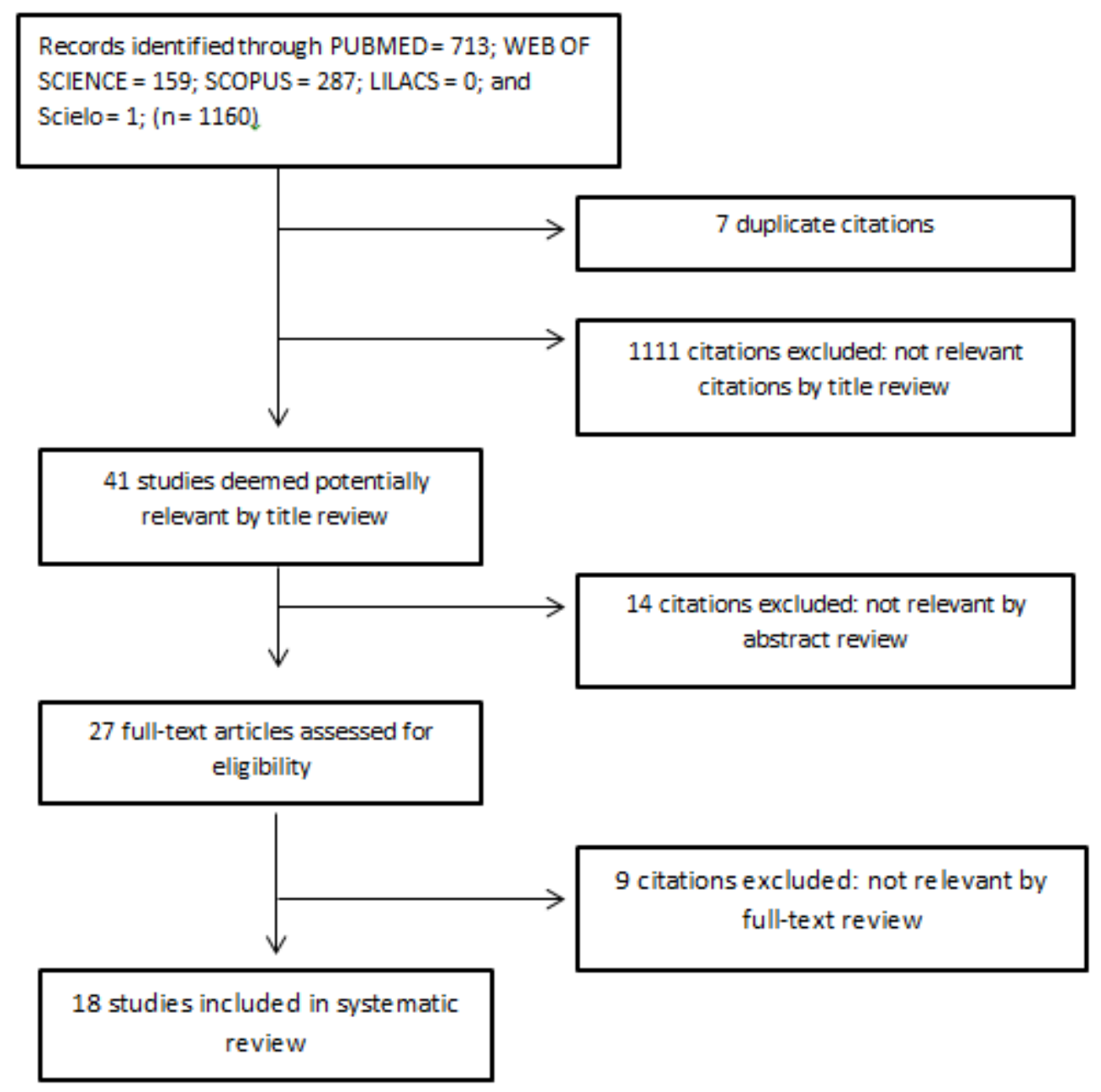

Figure 1

Flowchart of article selection process in accordance with PRISMA guidelines. 


\section{Group = I}

A. J. Barson. 1970

S. Vettivel.1991

M.A. Malas.2000

Y. Zalel.2006

O.J. Arthurs.2013

P. Manzone. 2019

Frequency

Heterogeneity: $I^{2}=0 \%, \tau^{2}=0.0389, \chi_{5}^{2}=0(p=1.00)$

\section{Group = II}

A. J. Barson.1970

S. Vettivel.1991

M.A. Malas. 2000

Y. Zalel.2006

Y. Perlitz.2010

Y.L. Huang.2013

O.J. Arthurs.2013

T. Lei.2014

S. Yang. 2017

J.Zhai.2018

P. Manzone. 2019

Frequency

Heterogeneity: $I^{2}=94 \%, \tau^{2}=0.0389, \chi_{10}^{2}=165.98(p<0.01)$

\section{Group = III}

A. J. Barson. 1970

Y. Zalel.2006

Y.L. Huang.2013

O.J. Arthurs.2013

T. Lei.2014

S. Yang. 2017

J.Zhai.2018

Frequency

Heterogeneity: $I^{2}=99 \%, \tau^{2}=0.0389, \chi_{6}^{2}=692.62(p<0.01)$

$0.10[0.03 ; 0.18]$

$0.39[0.16 ; 0.61]$

$0.29[0.05 ; 0.52]$

$0.27[0.04 ; 0.49]$

$1.00[0.97 ; 1.00]$

$0.14[0.00 ; 0.29]$

$0.74[0.68 ; 0.80]$

$0.44[0.28 ; 0.60]$

Group = IV

A. J. Barson.1970

Y. Zalel.2006

Y.L. Huang.2013

O.J. Arthurs. 2013

T. Lei.2014

J.Zhai.2018

Frequency

Heterogeneity: $I^{2}=93 \%, \tau^{2}=0.0389, \chi_{5}^{2}=76.88(p<0.01)$

\section{Frequency \\ $0.32[0.25 ; 0.40]$}

Heterogeneity: $I^{2}=100 \%, \tau^{2}=0.0389, \chi_{29}^{2}=6870.72(p=0)$

Residual heterogeneity: $I^{2}=97 \%, \chi_{25}^{2}=935.47(p<0.01) 0$

$0.50[0.40 ; 0.60]$

. $82 ; 0.99]$

$0.58[0.39 ; 0.77]$

$1.00[0.91 ; 1.00]$

$0.90[0.85 ; 0.95]$

$0.82[0.65 ; 0.98]$

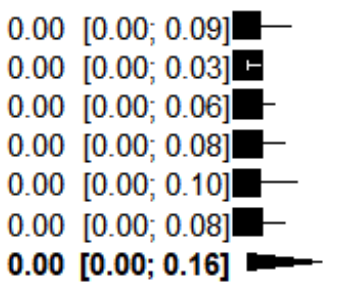




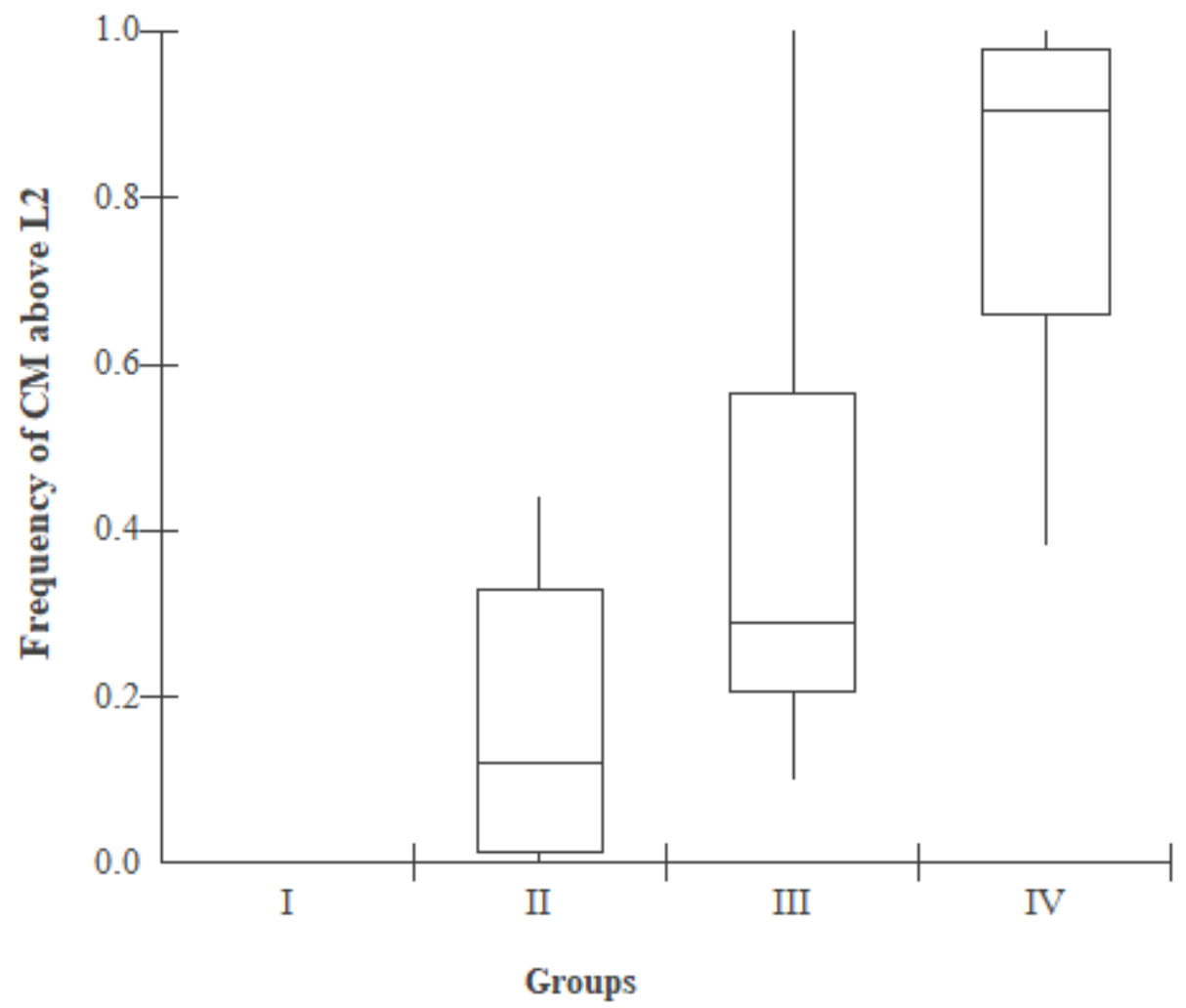

Figure 3

Average frequency of foetuses with CM at L2 or above by gestational age group.

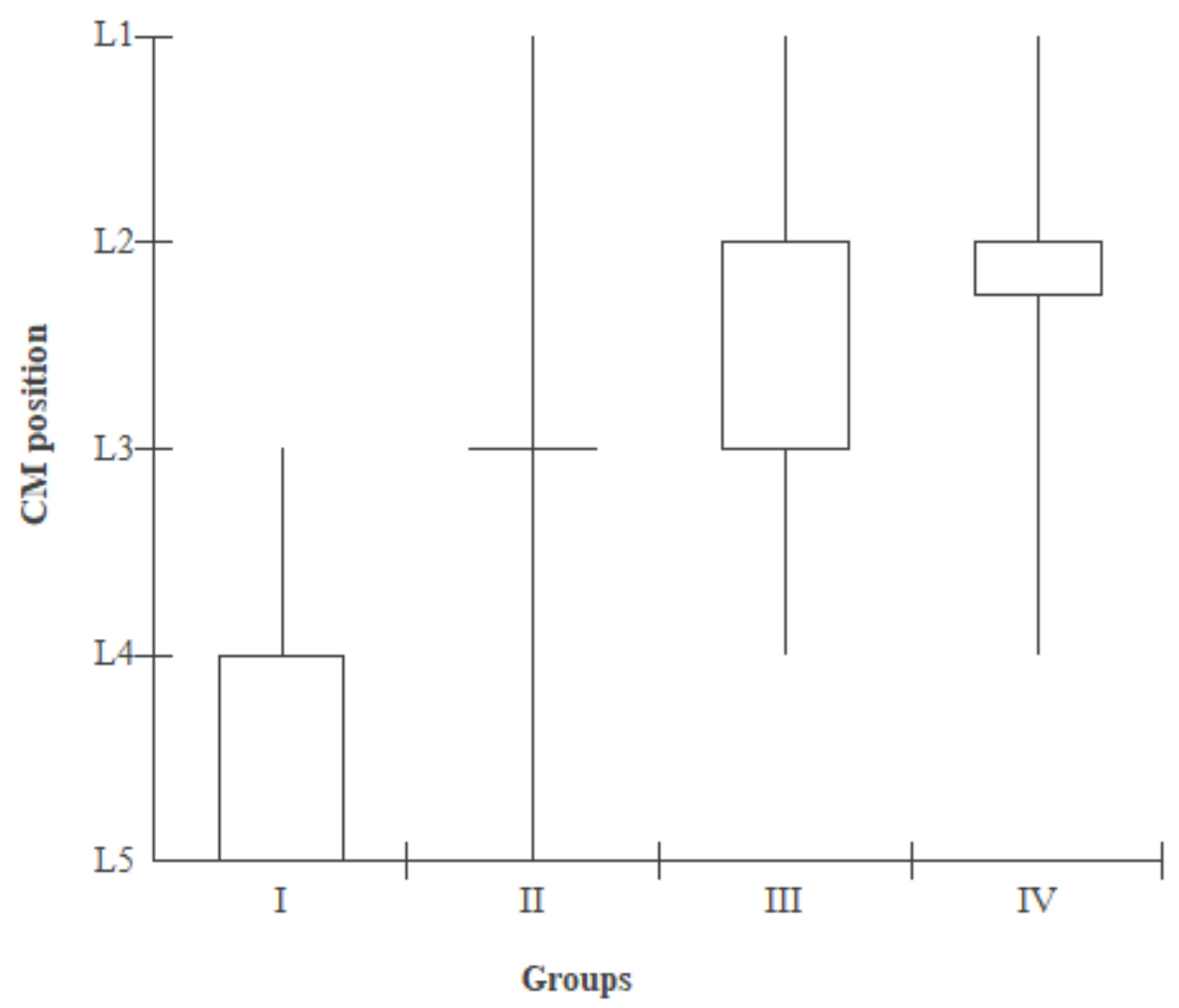


Figure 4

Average position of $\mathrm{CM}$ by gestational age group.

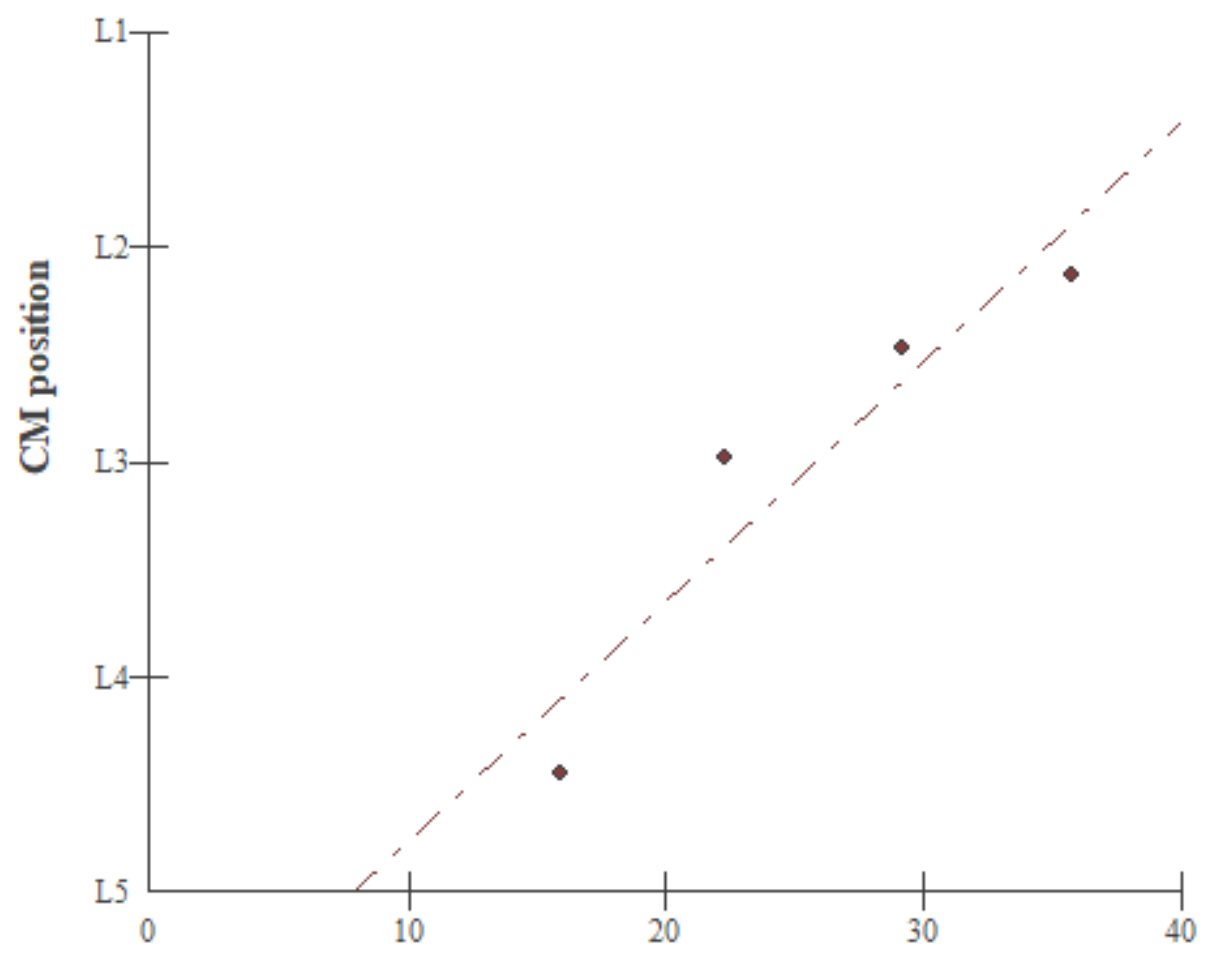

Gestational Age (Weeks)

\section{Figure 5}

Correlation between gestational age and CM position.
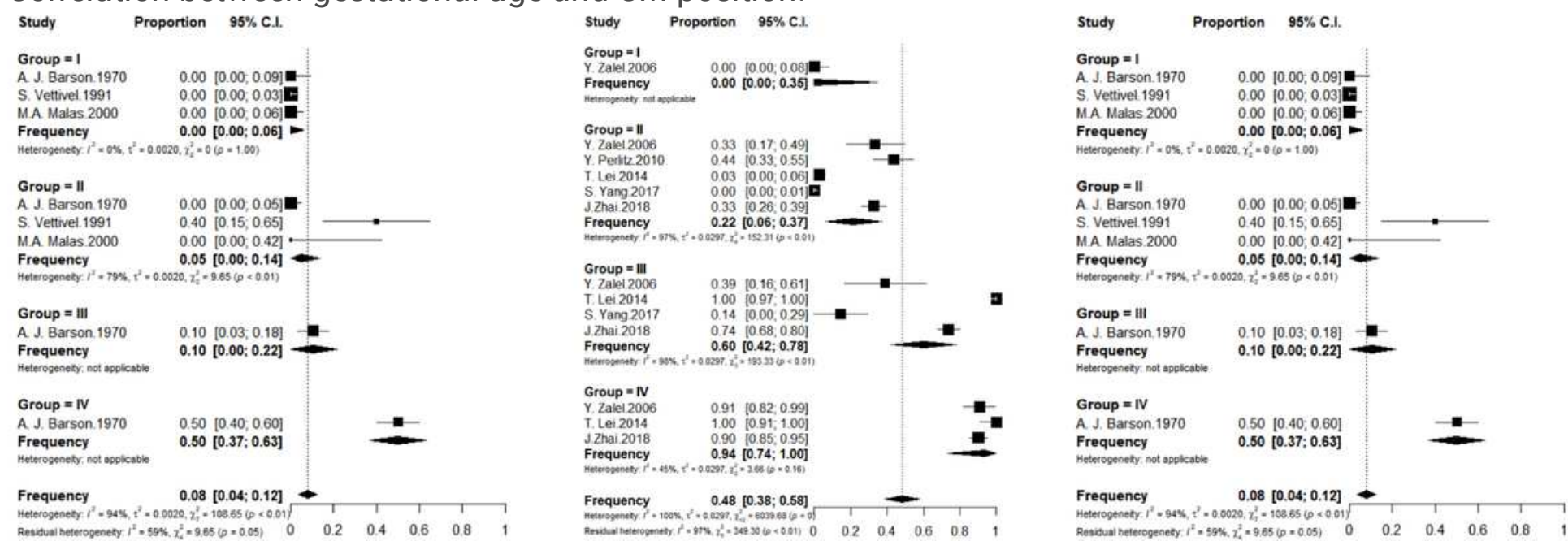

Figure 6

Frequency of foetuses with CM at L2 or above distributed by gestational age group and evaluation tool: post-mortem, sonography, and MRI (from left to right). 